\title{
COMUNICAÇÃO
}

\section{PRINCIPAIS DIFICULDADES ENCONTRADAS PELAS CERTIFICADORAS PARA RASTREAR BOVINOS}

\author{
Main difficulties found by certifiers of bovine traceability
}

Marcos Aurélio Lopes ${ }^{1}$, Glauber dos Santos ${ }^{2}$

\begin{abstract}
RESUMO
Esta pesquisa teve como objetivo realizar o levantamento das principais dificuldades encontradas pelas certificadoras para rastrear bovinos. Elaborou-se um questionário qualitativo semi-estruturado contendo 15 questões, sendo 14 de múltipla escolha e uma aberta, que foi enviado às 64 empresas certificadoras credenciadas pelo Ministério da Agricultura Pecuária e Abastecimento (MAPA). Destas, 40,68\% (24) responderam o questionário. As principais dificuldades encontradas pelas certificadoras foram: mudança freqüente das normas, falta de conscientização dos pecuaristas e controle da movimentação dos animais. Os maiores entraves encontrados pelas certificadoras na rastreabilidade bovina foram a desconfiança dos pecuaristas e a falta de incentivo do governo.
\end{abstract}

Termos para indexação: Bovinocultura de corte, certificação animal, segurança alimentar, SISBOV.

\begin{abstract}
This research had the aim of verifying the main difficulties found by the certifiers to trace bovines. It was prepared a qualitative semi-structured questionnaire containing 15 questions, 14 of multiple choice and an open one, which was sent to the 64 certifiers companies credenced by "Ministério da Agricultura Pecuária e Abastecimento"(MAPA). Only 40,68\% (24) of them answered. The main difficulties found by them were: frequent change of rules, lack of farmers conscientiousness and keeping track of the moving animals. The biggest impediments found by the certifiers, in the bovine traceability are: the distrust of the farmers and the lack of government incentive.
\end{abstract}

Index terms: Animal certification, beef cattle, food safety, SISBOV.

(Recebido em 7 de julho de 2006 e aprovado em 8 de janeiro de 2007)

A palavra rastreabilidade não consta ainda em nossos dicionários, mas indica a possibilidade de seguir os passos de alguma coisa, no caso, o histórico do animal desde o nascimento ou aquisição até o momento do seu consumo ou de uma de suas partes (REZENDE \& LOPES, 2004). Rastreabilidade é um sistema de controle de animais que permite sua identificação individual desde o nascimento até o abate, registrando todas as ocorrências relevantes ao longo de sua vida (SISTEMA..., 2002). De acordo com Schaeffer \& Caugant (1998) o conceito de rastreabilidade envolve a recomposição da história do produto alimentício. Pode, assim, ser útil estabelecer: a origem exata de uma produção de animais domésticos ou de vegetais, com os vários fatores que incorporam seu desenvolvimento; o histórico dos processos aplicados ao produto; a distribuição e a localização do produto acabado.

O mercado mundial de carne cada vez mais busca produtos de qualidade, sem risco sanitário, fruto das exigências dos consumidores. A abertura de novos mercados, ou manutenção dos mesmos, irá depender da adequação ou não do Brasil às normas impostas pelo cenário mundial, principalmente a Comunidade Européia. Como se trata de um bloco de países de muita importância na economia mundial, com grande poder de compra, todos os países que para lá exportam carne, estão sujeitos às exigências da Comunidade Européia.

A exigência da rastreabilidade da carne trouxe uma grande inquietação aos países exportadores e, em especial, ao Brasil devido ao tamanho do rebanho, às condições de criação do gado, à extensão do território brasileiro e à falta de utilização da tecnologia por parte da grande maioria de produtores ainda não acostumados com o uso da informática ou da gerência e controle integrados ao dia-adia de suas atividades.

Visando atender a essa demanda, o Ministério da Agricultura, Pecuária e Abastecimento (MAPA) publicou a Instrução Normativa $n^{\circ} 1$, de 9 de janeiro de 2002 (BRASIL, 2002a), que instituiu o Sistema Brasileiro de Identificação

\footnotetext{
1Doutor em Zootecnia, Professor - Departamento de Medicina Veterinária/DMV - Universidade Federal de Lavras/UFLA - Cx. P. 3037 - $37200-000$ Lavras, MG - malopes@ufla.br

'2Graduando em Zootecnia - Departamento de Zootecnia/DZO - Universidade Federal de Lavras/UFLA - Cx. P. 3037 - $37200-000$ - Lavras, MG glauber_zoo@yahoo.com.br - Bolsista de Iniciação Científica do CNPq.
} 
e Certificação de Origem Bovina e Bubalina (SISBOV) e a instrução normativa $\mathrm{n}^{\circ} 21$, de 26 de fevereiro de 2002 (BRASIL, 2002b), que estabeleceu as diretrizes, os requisitos, os critérios e os parâmetros para o credenciamento de entidades certificadoras junto ao SISBOV.

O SISBOV é o conjunto de ações, medidas e procedimentos adotados para caracterizar a origem, o estado sanitário, a produção e a produtividade da pecuária nacional e a segurança dos alimentos provenientes dessa exploração econômica, com o objetivo de identificar, registrar e monitorar, individualmente, todos os bovinos e bubalinos nascidos no Brasil ou importados (BRASIL, 2002a).

De acordo com o anexo I da Instrução Normativa ${ }^{\circ}$ 1 (BRASIL, 2002a), a base de dados informatizada será nacional e terá caráter oficial, ficando o gerenciamento de suas informações a cargo da SDA/MAPA e ela deverá conter informações atualizadas de animais, propriedades rurais e agroindústrias, todos identificados, registrados e cadastrados no SISBOV pelas entidades credenciadas. $\mathrm{O}$ controle da identificação e movimentação dos animais registrados será realizado pelas entidades certificadoras credenciadas.

A certificação representa um conjunto de procedimentos pelo qual uma entidade certificadora imparcial e independente - reconhece e/ou atesta que o produto atende a requisitos pré-estabelecidos. Deve ser feito por um organismo independente, que atesta através de um sistema de rastreabilidade onde atua como uma ferramenta de qualidade e fornece as diretrizes básicas de controle. Uma produção certificada não garante que um produto seja rastreável, porém um produto rastreado deve passar por um processo de certificação do sistema (IBA, 2003).

Para que o pecuarista possa implantar o SISBOV em sua produção e passe a ter o seu rebanho certificado necessário se faz escolher uma empresa certificadora credenciada e inscrever sua propriedade. Feito isso ele deverá informar a quantidade de animais que serão rastreados para que a empresa solicite a quantidade adequada de brincos à Base Nacional de Dados. Às empresas certificadoras cabem também coletar dados à respeito da data de nascimento e sexo dos animais, bem como aptidão, raça, movimentação de entrada e saída de animais, transferências, morte, manejo alimentar, sanitário e reprodutivo do rebanho, visando dar garantias de que o produto certificado está em conformidade com os requisitos especificados pelo MAPA (LOPES, 2005).
Na implantação do SISBOV, por ser ainda um sistema recente, tanto os pecuaristas, as certificadoras, bem como os frigoríficos vivenciaram algumas dificuldades. Diante disso, esta pesquisa teve como objetivo realizar o levantamento das principais dificuldades encontradas pelas certificadoras credenciadas pelo MAPA para rastrear animais. Especificamente pretendeu-se ainda: verificar se as empresas certificadoras receberam auditorias dos órgãos competentes; verificar se elas promoveram algum tipo de divulgação da rastreabilidade; verificar se o preço cobrado aumentou, diminuiu ou se manteve igual aos preços praticados no início dos trabalhos; conhecer quais são as principais reclamações dos pecuaristas e qual o grande entrave para a rastreabilidade bovina no Brasil. Esperou-se que, com o levantamento das dificuldades enfrentadas por este importante segmento do agronegócio carne, seja possível sugerir propostas para sanar as dificuldades.

Formulou-se um questionário qualitativo semiestruturado contendo 15 questões, sendo 14 de múltipla escolha e uma aberta, visando levantar as principais dificuldades encontradas pelas certificadoras credenciadas pelo Ministério da Agricultura Pecuária e Abastecimento (MAPA). Este questionário foi encaminhado às empresas através do endereço eletrônico e via correio, para as que não possuíam $e$-mail. A relação das empresas foi obtida no site http://extranet.agricultura.gov.br/ dev60cgi/rwcgi60?sisbov_cons\&certificadoras_web.rdf . Das 64 certificadoras credenciadas, $55(87 \%)$ possuíam $e$ mail. Destas, apenas $18 \%$ responderam ao questionário. Para as empresas que não responderam ao questionário encaminhado via $e$-mail e para as que não o possuíam, este foi encaminhado por correio convencional. Cinco correspondências retornaram porque o endereço não foi encontrado. Assim, 24 (40,68\%) empresas participaram respondendo o questionário.

$\mathrm{Na}$ formulação das primeiras perguntas, buscou-se saber qual o tipo de certificação e o tempo de atuação da empresa certificadora. As perguntas seguintes tiveram a intenção de saber se elas faziam algum tipo de divulgação da rastreabilidade animal e por qual meio. Foram feitas ainda perguntas referentes ao aspecto financeiro, tais como taxas cobradas, se elas sabiam quanto custa para o pecuarista rastrear e se o preço praticado na atualidade aumentará ou diminuirá em relação ao início de suas atividades. Por fim, foram feitas perguntas referentes à vantagens, dificuldades e reclamações feitas pelos pecuaristas, sendo a última pergunta destinada às sugestões para tornar a rastreabilidade efetiva no Brasil. 
A grande maioria $(87,5 \%)$ das empresas trabalhava exclusivamente com rastreabilidade animal, sendo que apenas uma $(12,5 \%)$ certificava animais e vegetais. De todas as que rastreavam animais, $75 \%$ rastreavam bovinos e bubalinos, 20,8\% rastreavam apenas bovinos e apenas $4,2 \%$ rastreavam outros animais (aves, suínos, caprinos e ovinos).

Quando perguntado sobre o tempo de atuação no mercado, 33,4\% das certificadoras disseram ter de 36 a 48 meses; $25 \%$ de 24 a 36 meses; $25 \%$ de 12 a 24 meses; e $16,6 \%$ de 1 a 12 meses. Esses números mostraram que, desde 2002, quando foi instituído o SISBOV, tinha ocorrido um aumento no número de certificadoras credenciadas pelo MAPA, evidenciando que esta atividade tinha se mostrado atrativa a vários empreendedores.

As quantidades de auditorias recebidas pelas certificadoras, por parte do MAPA, em função do tempo de atuação no mercado (Tabela 1) ocorreram muito espaçadamente, proporcionando falha na fiscalização. Os resultados evidenciaram que, no início, as vistorias eram mais freqüentes, com médias anuais de 1,17 e 1,13 nas empresas com 24 a 36 e 36 a 48 meses de atuação, respectivamente, enquanto que as empresas com menor tempo de atuação tinham recebido, em média, apenas 0,5 auditoria por ano. Uma possível explicação para este fato seria que o quadro de fiscais não tenha aumentado na mesma proporção da quantidade de certificadoras.

Quanto à divulgação da rastreabilidade, $79,1 \%$ disseram divulgar a rastreabilidade, utilizando diversos meios (Tabela 2), sendo os meios eletrônicos e o rádio os principais. O boletim técnico e a TV foram os meios com menor utilização pelas empresas certificadoras. Sobre "outros meios de divulgação", 28,7\% disseram divulgar a rastreabilidade em palestras nas universidades; banners; exposições; dias de campo e leilões.

Quanto aos quesitos monetários, existia uma grande distinção a um determinado padrão de "cobrança", por parte das empresas. Na tabela 3 podem ser observado quais são as taxas cobradas. A taxa utilizada pela maioria das certificadoras foi a taxa de rastreabilidade por animal $(95,8 \%) ; 4,2 \%$ das empresas cobravam esta despesa inclusa na cobrança de uma taxa única. A visita e o deslocamento do técnico foram cobrados por $58,3 \%$ e $45,8 \%$ das empresas, respectivamente.

Sobre os valores praticados hoje pelo serviço prestado, com relação aos preços praticados no início do trabalho da certificadora, $79,1 \%$ reduziram seus preços em $34,2 \%$. Tal fato, possivelmente, pode ser devido à quantidade de empresas que entraram no mercado de rastreabilidade animal aumentando a concorrência, o que levou a uma redução de preços. Cerca de $4 \%$ das certificadoras aumentaram em $10 \%$ este valor, e $16,6 \%$ mantiveram os mesmos preços. Todas as certificadoras responderam que sabiam quanto custa, para o pecuarista, rastrear um animal.

Com relação às principais dificuldades encontradas pelas certificadoras, percebe-se que a grande maioria das empresas consideraram como relevantes: as mudanças freqüentes das normas do SISBOV, o controle da movimentação dos animais e a falta de conscientização por

TABELA 1 - Quantidade de auditorias recebidas pelas certificadoras em função do tempo de atuação.

\begin{tabular}{ccccc}
\hline $\begin{array}{c}\text { Tempo de atuação } \\
\text { (meses) }\end{array}$ & $\begin{array}{c}\text { Quantidade } \\
\text { de empresas }\end{array}$ & $\begin{array}{c}\text { Quantidade } \\
\text { de auditorias }\end{array}$ & $\begin{array}{c}\text { Média } \\
\text { anual }\end{array}$ & $\begin{array}{c}\text { Média anual / Tempo } \\
\text { de atuação }\end{array}$ \\
\hline 1 a 12 & 1 & 0 & 0,00 & 0,5 \\
& 3 & 1 & 1,00 & 0,5 \\
\\
12 a 24 & 3 & 1 & 0,50 & \\
& 1 & 0 & 0,00 & 1,00 \\
\\
24 a 36 & 2 & 2 & 0,33 & 17 \\
& 2 & 1 & 0,67 & 1,13 \\
\hline
\end{tabular}

Ciênc. agrotec., Lavras, v. 31, n. 5, p. 1552-1557, set./out., 2007 
parte dos pecuaristas sobre a importância da rastreabilidade (Tabela 4). Quanto às mudanças freqüentes das normas, tal fato, pode ser constatado como real. Desde a sua implantação, em 10/01/2002, até 13/06/2005 (data em que este artigo foi concluído), 19 matérias (instruções normativas, portarias e circulares) já foram publicadas no Diário Oficial da União normatizando o funcionamento do SISBOV e estabelecendo regras, algumas das quais alterando o cronograma inicialmente estabelecido e alterando a permanência dos animais na Base Nacional de Dados. Considerando também que parcela significativa de pecuaristas tem demonstrado falta de conhecimento das normas, o MAPA, visando sanar esse problema, deveria publicar cartilha, de forma clara e objetiva, sobre o tema "rastreabilidade animal", à semelhança do que foi realizado no caso de alimentação de bovinos com cama de frango, doença da vaca loca, cana com uréia, entre outras.

TABELA 2 - Principais meios de divulgação da rastreabilidade utilizados pelas certificadoras.

\begin{tabular}{lc}
\hline Meios de divulgação & Freqüência $(\boldsymbol{\%})$ \\
\hline Internet & 70,8 \\
Rádio & 37,5 \\
Jornal & 33,3 \\
Mala direta & 29,1 \\
Boletim Técnico & 25,0 \\
TV & 20,8 \\
Outros & \\
$\quad$ Universidades & 8,3 \\
$\quad$ Banners & 8,3 \\
$\quad$ Exposições & 4,1 \\
$\quad$ Dia de campo & 4,1 \\
$\quad$ Leilões & 4,1 \\
\hline
\end{tabular}

TABELA 3 - Taxas cobradas pelas certificadoras.

\begin{tabular}{lc}
\hline \multicolumn{1}{c}{ Taxa } & Freqüência $(\boldsymbol{\%})$ \\
\hline Taxa de rastreamento por animal & 95,8 \\
Visita do técnico & 58,3 \\
Deslocamento do técnico & 45,8 \\
Brinco e botton & 50,0 \\
Anuidade & 16,6 \\
Inscrição & 8,3 \\
Taxa única & 4,1 \\
Outras & 8,3 \\
\hline
\end{tabular}

TABELA 4 - Principais dificuldades encontradas pelas certificadoras.

\begin{tabular}{lc}
\hline \multicolumn{1}{c}{ Dificuldades } & Freqüência (\%) \\
\hline $\begin{array}{l}\text { Mudança frequiente das normas } \\
\text { Controle da movimentação dos } \\
\text { animais }\end{array}$ & 50,0 \\
$\begin{array}{l}\text { Falta de conhecimento das } \\
\text { normas pelos pecuaristas }\end{array}$ & 33,3 \\
$\begin{array}{l}\text { Falta de conscientização dos } \\
\text { pecuaristas }\end{array}$ & 25,0 \\
$\begin{array}{l}\text { Desinteresse dos pecuaristas em } \\
\text { rastrear }\end{array}$ & 20,8 \\
$\begin{array}{l}\text { Controle da morte dos animais } \\
\text { Reclamação dos pecuaristas }\end{array}$ & 12,5 \\
sobre os preços & 0,0 \\
Outras & 20,8 \\
\hline
\end{tabular}

Em se tratando das normas vigentes sobre rastreabilidade no país, $41,6 \%$ das certificadoras as consideraram boas, mas que podiam melhorar; $50 \%$ consideraram ruim e afirmam que, quem as elaborou não tem experiência de campo; 4,2\% consideraram boa e que é isso mesmo que tem que ser feito; e 4,2\% consideraram ruins e que não foram feitas para um país como o Brasil. Um dado interessante foi que $40 \%$ das certificadoras sugeriram mudanças, tais como certificação da propriedade e maior fiscalização nas próprias certificadoras. Outras mudanças foram ainda sugeridas: aumentar o prazo para liberação para abate; maior rigor na apuração de denúncias das certificadoras; e padronização das instruções normativas.

Uma vez concedida a oportunidade para as certificadoras apontarem outras dificuldades, foram citadas as seguintes: falta de fiscalização no processo como um todo, principalmente, em auditorias no campo; concorrência desleal entre certificadoras (algumas deixam de realizar tarefas que encarecem o processo); descrédito dos pecuaristas; os pecuaristas reclamam da falta de incentivo por parte dos frigoríficos, já que eles agregaram valor ao produto e muitos não tinham recebido preço diferenciado pela arroba.

$\mathrm{Na}$ ótica das certificadoras, existiram algumas reclamações dos pecuaristas quando se tratou da implantação da rastreabilidade. As mais freqüentes foram: dificuldades na compreensão das normas do SISBOV $(66,6 \%)$, a rastreabilidade dificultava o manejo $(62,5 \%)$, não havia remuneração extra para a rastreabilidade: $(54,1 \%)$, a rastreabilidade não trazia benefícios $(41,6 \%)$, não existia 
mercado para animal rastreado $(8,1 \%)$ e dificuldades de entendimento das normas das certificadoras $(4,1 \%)$.

Quando perguntado às certificadoras o que elas consideraram como o grande entrave para a rastreabilidade alavancar no Brasil, os ítens mais citados foram a falta de incentivo por parte do governo, uma melhor remuneração por parte dos frigoríficos, desconfiança dos pecuaristas e o desinteresse dos consumidores brasileiros (Tabela 5). Concedida a oportunidade para as empresas apontarem outros entraves além da alternativas apresentadas, foram indicados ainda: falta de fiscalização para coibir fraudes e dar credibilidade ao processo, descredenciando as certificadoras corruptas e punindo os pecuaristas envolvidos; divulgação e esclarecimento aos produtores; descaso e desorganização por parte dos administradores do SISBOV; maior ônus para os pecuaristas. O custo, o que muitos pensavam ser o fator limitante para os pecuaristas não adotarem a rastreabilidade, foi um item que apenas $12,5 \%$ das certificadoras consideraram como entrave para os pecuaristas adotarem a rastreabilidade. Ou seja, na opinião das certificadoras, a maioria dos produtores não consideraram os custos com rastreabilidade um fator desestimulante.

Tais resultados mostraram que as certificadoras consideraram que ainda deviam trabalhar bastante para mostrar aos pecuaristas a importância da rastreabilidade para a cadeia do agronegócio "carne" e que tanto o governo como os frigoríficos deviam trabalhar em conjunto, para se conseguir um sistema de identificação animal eficiente.

Quando perguntado se as certificadoras acreditavam em um futuro promissor da rastreabilidade, apesar das dificuldades e entraves citados, 95,83\% responderam que sim, apresentando as seguintes justificativas: a rastreabilidade torna a cadeia mais competitiva devido à conscientização dos pecuaristas para a globalização e a necessidade de se conseguir novos mercados; a rastreabilidade é uma necessidade

TABELA 5 - Entraves da rastreabilidade no Brasil, segundo as certificadoras.

\begin{tabular}{lc}
\hline \multicolumn{1}{c}{ Entraves } & Freqüência (\%) \\
\hline Falta de incentivo do governo & 58,3 \\
Melhor remuneração dos frigoríficos & 50,0 \\
Desconfiança dos pecuaristas & 45,8 \\
Desinteresse dos consumidores & 20,8 \\
brasileiros & \\
Custo da carne rastreada & 8,3 \\
\hline
\end{tabular}

indiscutível, mas precisa ter maior fiscalização do governo (embora alguns técnicos do governo afirmem nem ter gasolina para ir às fazendas).

Concluindo não há outro caminho a não ser a rastreabilidade, tanto no aspecto comercial como gerencial pois a segurança alimentar será uma questão de prioridade, e os produtos, não rastreados, não terão mais espaço no mercado.

Por fim, no espaço destinado às sugestões para tornar a rastreabilidade uma grande ação no Brasil, 37,5\% das certificadoras apresentaram:

- divulgação, por parte do governo, sobre o que é e qual a importância da rastreabilidade;

- maior fiscalização em todos os segmentos (pecuaristas, certificadoras e frigoríficos);

- o animal deve ser rastreado do nascimento até o abate, sendo obrigatório, para toda propriedade a venda do seu animal para um frigorífico;

- necessidade de pessoas mais treinadas no MAPA, para trabalhar com o SISBOV, e que essas pessoas tenham consciência das dificuldades das certificadoras, produtores e frigoríficos;

- adoção de um planejamento de marketing instituído pelo governo, visando o mercado interno;

- adoção obrigatória da identificação eletrônica associada a um reembolso do investimento pelos frigoríficos;

- maior comprometimento do governo e da sociedade;

- maior organização da cadeia;

- melhor remuneração aos produtores.

As principais dificuldades encontradas pelas certificadoras foram as mudanças freqüentes das normas do SISBOV, o controle da movimentação dos animais e a falta de conscientização, por parte dos pecuaristas, da importância da rastreabilidade.

Apesar das dificuldades e entraves encontrados, essas empresas acreditavam em um futuro promissor para a rastreabilidade. Isso ficou evidenciado porque $100 \%$ delas fizeram divulgação da rastreabilidade animal e uma parcela significativa apresentou sugestões para tornar a rastreabilidade uma grande ação no Brasil.

\section{REFERÊNCIAS BIBLIOGRÁFICAS}

BRASIL. Ministério da Agricultura, Pecuária e Abastecimento. Instrução normativa n. 1, de 9 de janeiro de 2002. Diário Oficial da União, Brasília, p. 6, 10 jan. 2002a. Seção 1.

BRASIL. Ministério da Agricultura Pecuária e Abastecimento. Instrução normativa n. 21, de 26 de fevereiro de 2002. Diário Oficial da União, Brasília, p. 1, 27 fev. 2002b. Seção 1. 
IBA, S. K. Um panorama da rastreabilidade dos produtos agropecuários do Brasil destinados à exportação: carnes, soja e frutas. 2003. Monografia (Graduação) - Escola Superior de Agricultura "Luiz de Queiroz", Universidade de São Paulo, Piracicaba, 2003.

LOPES, M. A. Rastreabilidade na bovinocultura. 2. ed. Lavras: FAEPE/PROEX, 2005. 76 p. Apostila.

RESENDE, E. H. S.; LOPES, M. A. Identificação, certificação e rastreabilidade na cadeia da carne bovina $e$ bubalina no Brasil. Lavras: UFLA, 2004. 39 p. (Boletim agropecuário, 58).

SCHAEFFER, E.; CAUGANT, M. Traçabilité guide pratique pour l'agriculture el'industrie alimentaire. [S.l.]: ACTA-ACTIA, 1998.

SISTEMA integrado de rastreabilidade bovina. Disponível em: 〈http://www.sirb.com.br/pg_rastreabilidade.php>. Acesso em: 12 jun. 2002. 